\title{
STUDY ON IN-SERVICE INSPECTION PROGRAM AND METHOD FOR FUEL HANDLING SYSTEM OF RDE
}

\author{
Alim Mardhi $^{1 *}$, Andryansyah ${ }^{1}$, MUdi Haryanto ${ }^{1}$, TOPan Setiadipura ${ }^{1}$, \\ ARI NUGROHO ${ }^{2}$ \\ ${ }^{1}$ Center for Nuclear Reactor Technology and Safety - BATAN, Indonesia \\ ${ }^{2}$ Center for Assessment of Nuclear Energy System - BATAN, Indonesia \\ *Corresponding author:alim_m@batan.go.id
}

(Received: 03 January 2021; Accepted: 21 January 2021; Published on-line: 01 March 2021)

\begin{abstract}
One of the main programs that should be established on the designing process of the fuel handling system is to establish an in-service inspection program for maintaining the integrity of the system, structure and component during service lifetime. The most important role of in-service inspection is the nondestructive examination techniques. The objective of this study is to propose a preliminary program for examining the integrity of the fuel handling system during operation and determining the best method to confirm the defects. The proposed programs are described as follows, defining the operating environment of the fuel handling system, identifying the material characteristics during operation which indicates to promote the defects, and selecting the appropriate method of non-destructive examination and analysis technique for such kind of defects. The proposed in-service inspection program is expected to give significant additional value to the fuel handling system design of RDE.
\end{abstract}

KEYWORDS: Fuel Handling System, In-Service Inspection, HTGR.

\section{INTRODUCTION}

The fuel handling system (FHS) is one of the main systems of Reaktor Daya Experimental (RDE), a design of Experimental Power Reactor type high-temperature gas reactor (HTGR). The main function of FHS is to transport and circulate fuel elements type pebble bed with diameter $60 \mathrm{~mm}$ into the reactor core through the $65 \mathrm{~mm}$ inner diameter of ascending and forwarding piping system and removes fuel elements from the fuel discharge tube of the reactor. The FHS operates under a helium gas carrier system with a maximum temperature of $2500 \mathrm{C}$ and operational pressure at 30 bars. During normal operation, the flow rate of transporting gas in various segments of the piping system, gas carrier temperature, gas pressure in individual pipeline segments, and the pressure drop across the filter in the pneumatic fuel forwarding system should be monitored. All these environmental conditions can promote degradation of the system which can be detected as early as possible in the inspection program. The in-service inspection program of FHS should establish for maintaining the integrity of the system, structure and component during service lifetime. The main purpose of this program is to find service-related to degradations of equipment such as corrosion, erosion, fatigue, and creep.

The objective of this study is to propose the preliminary program of ISI for examining the integrity of fuel handling system during operation and determining the best method to confirm the defects. 


\section{FUEL HANDLING SYSTEM (FHS) DESIGN}

The main equipment of FHS is the charging control system, discharging control system, fuel separator, pneumatic elevator, and burn-up measurement station. In normal operation, the flow process of FHS describes in Figure 1. The fuel handling equipment continuously supplies the reactor core with fuel elements and removes fuel elements from the fuel discharge tube of the reactor. The overwhelming majority of fuel elements discharged from the reactor should be returned to the core (recirculated), as these fuel elements have not yet reached final burnup. On the opposite, spent fuel as well as fuel element fragments and out-of-shape fuel elements discharged from the reactor should be removed from the fuel. Fuel elements removed from the fuel cycle should be replaced 1:1 by new fuel elements. The daily requirement for new fuel elements is approximately 25 per full-load day.

Based on concept design RDE, all the materials for the FHS are selected based upon the required physical-mechanical, lifetime and cost characteristics, manufacturability, and admissibility for being used in the nuclear power industry. The candidate material of FHS is made of austenitic class stainless steel types $12 \mathrm{Cr} 18 \mathrm{Ni} 10 \mathrm{Ti}, 08 \mathrm{Cr} 18 \mathrm{Ni} 10 \mathrm{Ti}$ with the chemical composition as shown in Table 1.

Table 1: Chemical Composition, $\%$ Fe $(\sim=69,8 \%)$

\begin{tabular}{lllllllllll}
\hline $\mathbf{C}$ & $\mathbf{M n}$ & $\mathbf{S i}$ & $\mathbf{C r}$ & $\mathbf{N i}$ & $\mathbf{M o}$ & $\mathbf{V}$ & $\mathbf{T i}$ & $\mathbf{P}$ & $\mathbf{S}$ & $\mathbf{C u}$ \\
\hline 0.12 & 1.21 & 0.47 & 17.42 & 10.30 & 0.203 & $<0.003$ & $<0.47$ & $<0.02$ & $<0.02$ & $<0.147$ \\
\hline
\end{tabular}

These materials are Russian type austenitic stainless steel which are notable for their high quality and characterized by a low carbon content, high plasticity with a low tendency to crack formation in welded joints. Currently, other types of austenitic stainless steel 300 series are still investigated to be alternative candidate material of the FHS component.

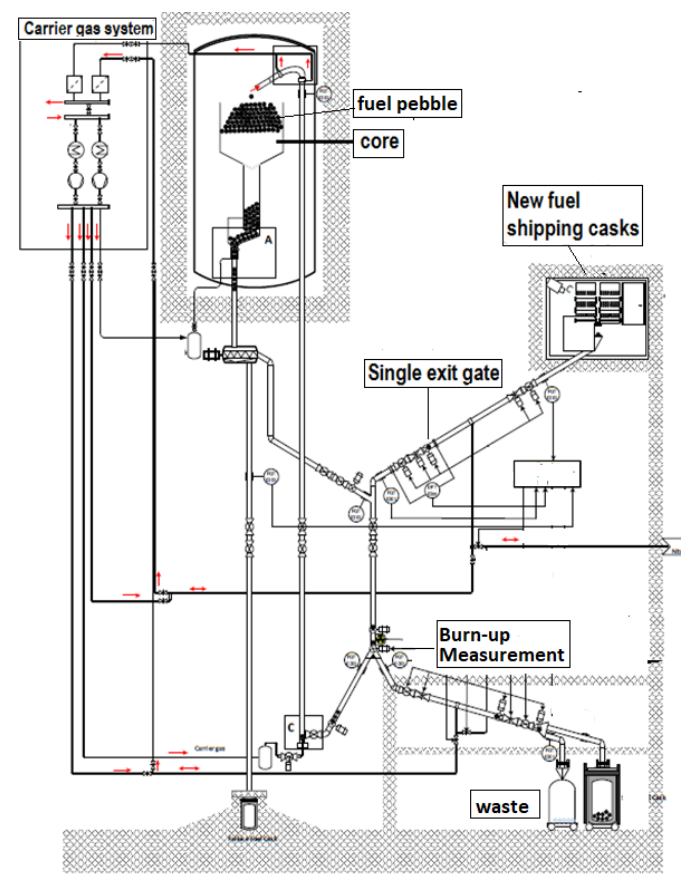

Fig. 1. Flow Process of FHS RDE 


\section{POTENTIAL MATERIAL DEGRADATION MECHANISM}

There are a few research have been conducted to investigate the effects of environmental operation which may promote the degradation and aging mechanism of metals structure in high-temperature gas reactors (HTGR) components [1-6]. One of the previous research proposed that the effects of high-temperature helium with gas impurities may cause stress corrosion to crack initiation and growth rate, crevice corrosion crack initiation and growth rate, and cyclic crack growth rate[6]. Due to the helium behavior is insoluble in metal, the gas molecule tends to precipitate as clusters and nanometer-scale bubbles even at relatively low temperatures[5]. These bubbles have been suspected to promote the void formation in the micro-grain boundary and initiate the crack.

The other environmental effects are coming from irradiated fuel which is circulated and transferred in the fuel handling system. This effect of radiation may change the mechanical properties of metals to be brittle. Specifically, for FHS material, these irradiation effects are still needed to be investigated further. The fluctuation of loads from pressure, the temperature during operation, and external load such as seismic, and vibration should promote the void to grow into cracks and initiate fatigue and creep failure as potential degradation mechanism in FHS.

\section{PROPOSED ISI PROGRAM AND METHOD}

The general objective of the in-service inspection (ISI) program is to avoid the failure in engineering components by recognizing the material failure mechanism and how to detect it as early as possible [7-10]. There are three technical elements [11]which are influence in-service inspection program and method development. The first technical element is knowledge of plant manufacture such as manufacturing methods, manufacturing codes and standards, welding process, and non-destructive test (NDT) for construction and commissioning inspection. Knowledge of plant operation is the second technical element which includes critical temperature and pressure and environmental operation. The third one is knowledge of plant failure mechanism which covers material degradation mechanism and stress analysis and fracture mechanics theory. The quality of in-service inspection is depending on those technical elements.

The ISI program of FHS starts with establishing the acceptance limit of a defect in FHS components. Some code and standard have been adopted as reference for determining acceptance limits such as ASME section III division I, BS7910, API 579 and ASTM E164 (Standard Practice for Ultrasonic Contact Examination of Weldments), ASTM E709 (Standard Guide for Magnetic Particle Examination), and ASTM E165 (Standard Test Method for Liquid Penetrant Examination)[2]. Each code and standard may be used wisely due to the acceptance criteria and critical limit in the code are vary depending on the type of material, service condition, and failure theory behind the use analytical formula. The second step of the ISI program is selecting the appropriate NDE method for investigating the actual condition of the material degradation mechanism. Based on the previous section, it has been investigated that the potential types of material degradation mechanisms in FHS are fatigue and creep. Since the characteristic of fatigue and creep failures and in the early phase of degradation is difficult to observe, the fracture mechanics theory and creep strength analysis can be applied for estimating crack propagation in components. Visual NDE methods such as dye penetrant (DP) and magnetic particle inspection (MPI) may be used for detecting the surface crack. Ultrasonic, acoustic emission, eddy current, and radiography are suitable for detecting cracks under the subsurface. Replica metallography is used to investigate a void form of creep failure. Advance 
NDE technique such as infrared camera, strain measurement is used to increase the detection capability of defects in the critical part of FHS component[12-15].

After the cracks or defects have been observed, the next step is checking the limit tolerances based on the acceptance criteria and code requirement. Furthermore, an analytical solution of existing defects or generate modeling simulation of defects in components by using appropriate computer programs may increase the validity of in-service inspection and consider additional value for predictive remaining life assessment. The last step is reporting all the evidence as well as the recommendation for accepting or rejecting the defects. These recorded data become the main reference for the next in-service inspection program and display the status of safety operation level.

\section{CONCLUSION}

Helium gas carriers and irradiated fuel have been suspected to initiate the defects in components. The service pressure and temperature propagate the defects to fatigue and creep as the most potential failure mechanism in FHS. The important parts of the ISI program are determining the appropriate codes and standards for acceptance criteria of defects, finding, and measuring the existing defect by using the NDE technique, comparing the finding defects to the tolerance limit, and reporting all of the evidence. Three technical elements that are needed to have for developing the ISI program are knowledge of plant manufacturing, knowledge of plant operation, and knowledge of plant failure mechanism. The preliminary study of the inservice inspection (ISI) program for examining the existing defect which may occur during service operation of fuel handling system (FHS) has a significant contribution to figuring out the detail part of design RDE.

\section{ACKNOWLEDGEMENT}

Authors wishing to thanks to Center for Nuclear Reactor Technology and Safety - BATAN, and the Indonesia Ministry of Research, Technology and High Education (KEMENRISTEKDIKTI) for financial support through the research.

\section{REFERENCES}

[1] S. Şahin and H. Mehmet Şahin, "1.20 Nuclear Energy," in Comprehensive Energy Systems, Elsevier, 2018, pp. 795-849.

[2] V. Shah, S. Majumdar, and K. Natesan, "Review and Assessment of Codes and Procedures for HTGR ...," 2003.

[3] I. Pioro and R. Duffey, "Current and future nuclear power reactors and plants," in Managing Global Warming, Elsevier, 2019, pp. 117-197.

[4] "Chapter Radiation Void Swelling Effects in Metals : and Irradiation Creep."

[5] A. Hojná, "Overview of Intergranular Fracture of Neutron Irradiated Austenitic Stainless Steels,” Metals (Basel)., vol. 7, no. 10, p. 392, 2017, doi: 10.3390/met7100392.

[6] N. C. Chokshi, C. A. Greene, J. Muscara, and M. Srinivasan, "Materials Research Needs for Advanced Reactors," pp. 1-9, 2003.

[7] S. A. Ali and G. Bagchi, "Risk-informed inservice inspection," Nucl. Eng. Des., vol. 181, no. 1-3, pp. 221-224, May 1998, doi: 10.1016/S0029-5493(97)00347-6.

[8] S. Takaya, Y. Kamishima, H. Machida, D. Watanabe, and T. Asayama, "Determination of in-service inspection requirements for fast reactor components using System Based 
Code concept," Nucl. Eng. Des., vol. 305, pp. 270-276, Aug. 2016, doi: 10.1016/j.nucengdes.2016.05.028.

[9] I. Aho-Mantila et al., "Lifetime prediction techniques for nuclear power plant systems," in Nuclear Corrosion Science and Engineering, Elsevier, 2012, pp. 449-470.

[10] M. Stewart and O. T. Lewis, "In-Service Inspection by Nondestructive Examination (NDE)," in Pressure Vessels Field Manual, Elsevier, 2013, pp. 347-424.

[11] C. Matthews, "Mechanical In-Service Inspection."

[12] D. J. Naus, "Inspection of Nuclear Power Plant Structures - Overview of Methods and Related Applications," no. May, 2009.

[13] S. Ravi, K. Laha, S. Sakthy, M. D. Mathew, and A. K. Bhaduri, “An experience with inservice fabrication and inspection of austenitic stainless steel piping in high temperature sodium system," Nucl. Eng. Des., vol. 284, pp. 300-307, 2015, doi: 10.1016/j.nucengdes.2014.12.034.

[14] "Application of Acoustic Emission and Other Online Monitoring Technologies to High Temperature Gas Reactors," no. January, 2012.

[15] S. Ravi et al., "Influence of flowing sodium on creep deformation and rupture behaviour of 316L(N) austenitic stainless steel," J. Nucl. Mater., vol. 427, no. 1-3, pp. 174-180, Aug. 2012, doi: 10.1016/j.jnucmat.2012.04.030. 